\title{
SUSCEPTIBILITY OF STRICT AND FACULTATIVE ANAEROBES ISOLATED FROM ENDODONTIC INFECTIONS TO METRONIDAZOLE AND $\beta$-LACTAMS
}

\author{
Elerson GAETTI-JARDIM JÚNIOR ${ }^{1}$, Luís Fernando LANDUCCI², Samira Âmbar LINS³, \\ Evanice Menezes Marçal VIEIRA ${ }^{4}$, Sérgio Ricardo de OLIVEIRA $^{5}$
}

\author{
1- PhD, Department of Pathology and Propedeutics Clinic, Dental School of Araçatuba, São Paulo State University, Araçatuba, SP, Brazil. \\ 2- PhD, Professor of Microbiology and Immunology, UNIRP. \\ 3- MSc, Professor, School of Dentistry of Santa Fé do Sul. \\ 4- MSc, Postgraduate student, Professor of Pathology, UNIC. \\ 5- Graduate student, Dental School of Araçatuba, São Paulo State University, Araçatuba, SP, Brazil.
}

Corresponding address: Dr. Elerson Gaetti Jardim Júnior - Faculdade de Odontologia de Araçatuba-UNESP - Rua Jose Bonifácio, 1193

16015-500 Araçatuba, SP, Brazil - Phone: +55-18-3636-3200 ext. 3447 - e-mail: egaettij@foa.unesp.br

Received: December 13, 2006 - Modification: April 17, 2007 - Accepted: August 27, 2007

\begin{abstract}
$F$

ndodontic infections are mixed aerobic-anaerobic infections and several microbial groups associated to these pathologies are also involved in orofacial infections. The goal of this study was to evaluate the susceptibility of microorganisms isolated from endodontic infections to $\beta$-lactams and metronidazole and verify the production of $\beta$-lactamases. Clinical specimens were collected from 58 endodontic infections of 52 patients. The microorganisms were isolated in selective and non-selective culture media, under anaerobiosis and aerobiosis, and identified using biochemical methods. In the susceptibility tests, it was used an agar dilution method, and Wilkins-Chalgren agar enriched with blood, hemin and menadione for the anaerobes, while MuellerHinton agar was employed for the facultative anaerobes. The production of $\beta$-lactamases was evaluated through the biological and chromogenic cephalosporin methods. All tested isolates were sensitive to imipenem and $99.3 \%$ to amoxicillin/clavulanate association, while $16.1 \%$ showed resistance to amoxicillin and penicillin G, and $4.89 \%$ to cefoxitin. Resistance to metronidazole was just found in facultative anaerobes. Production of $\beta$-lactamases was detected in $18.2 \%$ of the isolates and presented a correlation with resistance to $\beta$-lactams.
\end{abstract}

Uniterms: Infection; Antibacterial agents; $\beta$-lactams.

\section{INTRODUCTION}

Endodontic infections are mixed aerobic-anaerobic infections characterized by a correlation between the virulence of specific microorganisms and the host's immune system ${ }^{23}$. In the pathogenesis of these infections, specific microbial groups play a relevant role, particularly strict tive anaerobes, which are also associated to their clinical symptomatology ${ }^{8,10}$. Such mixed infections may afford an optimum situation for the exchange of genetic elements between bacterial species.

The clinical outcome of endodontic treatment depends on controlling the microbial biofilm that is established inside the root canal system by means of instrumentation and antibacterial irrigation. However, residual microorganisms in the root canals are frequently involved in orofacial infections ${ }^{25}$. In the treatment of these infections, systemic antibiotics can be prescribed to prevent the spread of infection and onset of serious complications ${ }^{3}$. However, empirical prescription of antimicrobials as part of endodontic management is problematic, given the diversity of potential pathogens and their different sensitivity drugs.

The determination of in vitro antimicrobial susceptibility may be important in certain situations, for example, to monitor patterns of susceptibility and resistance in the population and to aid in the selection of an appropriate antibiotic when indicated in the endodontic treatment ${ }^{17}$. Moreover susceptibility tests for anaerobes are not routine in Brazil. Therefore, the objective of this study was to evaluate the susceptibility of bacteria isolated from endodontic infections to $\beta$-lactams and metronidazole and evaluate the production of $\beta$-lactamases.

\section{MATERIALAND METHODS}

This study was approved by the Ethics in Human Research Committee of the Dental School of Araçatuba (FOA 01638). 


\section{Patients}

The population of this study consisted of 33 patients, presenting at the Dental School of Araçatuba of São Paulo State University (UNESP), and 19 patients attending private clinics for endodontic treatment. Medical histories revealed that all patients were in good general health. Patient ages ranged from 19 to 61 years (mean age $=31.5$ ). At the first visit, written informed consent was obtained from each patient before enrolment in the study. Patients who had received antibiotics 3 months before the root canal therapy and teeth with a periodontal pocket probing depth greater than $4 \mathrm{~mm}$ were excluded.

\section{Clinical Signs and Symptoms}

It was recorded the presence of carious tissue, pulp status, presence and clinical conditions of restorations, pain on occlusion, tenderness to percussion or palpation, swelling and presence of periapical radiolucency, mobility, periodontal pocket probing depth, presence of a sinus of endodontic origin, intracanal condition, such as a dry canal or the presence of exudates $^{10}$. The diagnosis of endodontic pathology was performed as described by Sigurdsson ${ }^{26}$.

\section{Clinical Samples}

The specimens were taken from 58 endodontic infections of 52 patients. Clinical samples were collected from 32 teeth with chronic endodontic infection, 10 teeth presenting acute endodontic infection with acute periapical abscess and from 16 teeth presenting exacerbated periapical lesions and pulpal necrosis. After anesthesia, a rubber dam was placed. The operative field was disinfected and antisepsis of tooth enamel was performed ${ }^{10}$. Access to the root canal system was gained with sterile burs. In addition, sterile saline delivered through a manual irrigation to avoid contamination from dental unit waterlines. After removal of carious dentin, canal patency was established with minimal instrumentation and without use of any chemically active irrigant. Thereafter, the canal was soaked with VMGAIII transport solution and clinical specimens were collected by using sterile paper points, which were introduced into the full canal length, as previously determined with a preoperative radiograph. The paper points were kept in place for 30-60 seconds and were transferred to VMGA III.

In the laboratory, aliquots of VMGA III were submitted to serial 10 fold dilutions and were plated on Fastidious Anaerobic Agar (FAA) supplemented with yeast extract (0.5\%), hemin (5 $\mu \mathrm{g} / \mathrm{mL})$, menadione (1 $\mu \mathrm{g} / \mathrm{mL})$ and 5\% horse blood, crystal violet erythromicin agar (CVEA), FAA + nalixidic acid (0.001\% $\mathrm{w} / \mathrm{v})+$ vancomycin $(0.5 \mathrm{mg} / \mathrm{L})$ and $5 \%$ horse blood, FAA + vancomycin $(0.5 \mathrm{mg} / \mathrm{L})$ and kanamycin $(0.016 \mathrm{mg} / \mathrm{L})$, and incubated under anaerobiosis $\left(90 \% \mathrm{~N}_{2}+10 \% \mathrm{CO}_{2}\right)$, at $37^{\circ} \mathrm{C}$, for 14, 04, 04 and 14 days, respectively ${ }^{11}$. The same dilutions were plated on horse blood Brain Heart Infusion Agar and on MacConkey agar, incubated aerobically, at $37^{\circ} \mathrm{C}$ for 2 days.

Pure cultures were obtained and the isolates were subjected to morphocellular and morphocolonial analyses, respiratory test and catalase assay. This was followed by identification of the isolates at the genus level and, whenever possible, at the species level, using commercial kits ${ }^{10}$ (BioMérieux SA, Marcy-
l'Etoile, France) and carbohydrate fermentation.

\section{Microorganisms}

A total of 119 isolates of strict and facultative anaerobic bacteria were subjected to the susceptibility tests. The bacterial inocula were standardized in $10^{5}$ cells and transferred to the Petri plates containing the antimicrobials and the control plates (without drugs), using a Steer's replicator (Cefar Ltda, São Paulo, SP, Brazil). The minimum inhibitory concentration (MIC) was defined as the smallest concentration of the drug able to completely inhibit the bacterial growth.

F. nucleatum ATCC 10953 and ATCC 25586, E. lentum ATCC 43055, and B. fragilis ATCC 23745 were used as reference strains for quality control in the assays involving strict anaerobes, while E. coli ATCC 25922, S. aureus ATCC 29213, P. aeruginosa ATCC 27853, and E. faecalis ATCC 29212 were used in the assays involving facultative anaerobes. The test and control dishes were incubated anaerobically $\left(90 \% \mathrm{~N}_{2}+10 \% \mathrm{CO}_{2}\right)$ or aerobically at $37^{\circ} \mathrm{C}$, for 48 hours.

\section{Antimicrobial susceptibility tests}

The following antimicrobial drugs were tested: amoxicillin (Bayer S.A., São Paulo, SP, Brazil), amoxicillin/clavulanic acid (Smithkline Beecham Brasil Ltda, São Paulo, SP, Brazil), cefoxitin (Merck Sharp \& Dohme, São Paulo, SP, Brazil), imipenem(Merck Sharp \& Dohme, São Paulo, SP, Brazil), benzylpenicillin (Fontoura-Wyeth S.A., São Paulo, Brazil) and metronidazole (Laboratórios Pfizer Ltda, Guarulhos, SP, Brazil). The breakpoints used for interpretation were generally those recommended by the NCCLS ${ }^{20}$. Antimicrobials were tested in concentrations that ranged from $0.06 \mu \mathrm{g} / \mathrm{mL}$ to $512 \mu \mathrm{g} / \mathrm{mL}$. The tests were carried out by agar dilution method. Wilkins-Chalgren agar supplemented with horse blood, hemin $(5 \mu \mathrm{g} / \mathrm{mL})$ and menadione ( $1 \mu \mathrm{g} / \mathrm{mL})$ was used for strict anaerobes and Mueller-Hinton agar was used for facultative anaerobes.

\section{Detection of $\boldsymbol{\beta}$-lactamases}

All microorganisms able to resist at least $0.5 \mu \mathrm{g} / \mathrm{mL}$ of any of the tested $\beta$-lactms were submitted to tests to evaluate the production of $\beta$-lactamases, using biological ${ }^{24}$ and chromogenic cephalosporin methods ${ }^{6}$. These two methods were performed because nitrocefin-based $\beta$-lactamase assays have not proven useful in detecting $\beta$-lactamase production by some anaerobes ${ }^{6}$.

A chromogenic cephalosporin $\beta$-lactamase assay using Cefinase disks was performed according to the manufacturer's instructions. Briefly, 6-mm-diameter filter paper disks impregnated with nitrocefin were moistened with $0.85 \% \mathrm{NaCl}$, and several isolated colonies of test organisms were transferred to the disk. Disks were examined for the appearance of a pinkred coloration for up to $10-60 \mathrm{~min}^{6}$.

In the biological method ${ }^{24}, 20 \mu \mathrm{L}$ of cultures of the resistant isolate were plated on the surface of Wilkins-Chalgren agar, containing $0.5 \mu \mathrm{g} / \mathrm{mL}$ of the tested â-lactam. These plates were then incubated anaerobically or aerobically at $37^{\circ} \mathrm{C}$ for $48 \mathrm{~h}$. After this incubation period, the cultures were exposed to chloroform fumes for $20 \mathrm{~min}$. and then covered with $3 \mathrm{~mL}$ of semi-solid brain heart infusion (BHI) agar (0.7\% agar) previously inoculated with $10^{6}$ cells of Streptococcus pyogenes FOA-94F14 
sensitive to all tested $\beta$-lactams in a concentration of $\leq 0.06 \mu \mathrm{g} /$ $\mathrm{mL}$. The Petri dishes were then incubated under aerobiosis for $24 \mathrm{~h}$ at $37^{\circ} \mathrm{C}$. After incubation, presence or absence of growth of the streptococcal strain was checked. The presence of this halo of growth was indicative of the degradation of the $\beta$ lactam. Bacteroides fragilis ATCC 43858 was used as the positive control of â-lactamase production.

\section{RESULTS}

Susceptibility to antimicrobial agents was evaluated on two isolates of Actinomyces naeslundii, four isolates of $A$. israelii, one isolate of A. odontolyticus, two isolates of Actinomyces sp., four Bacteroides sp., three isolates of Eubacterium sp., one isolate of E. lentum, five Enterococcus faecalis and Fusobacterium sp., twelve $F$. nucleatum and Peptostreptococcus sp., three $P$. anaerobius, two $P$. asaccharolyticus, four isolates of $P$. micros, three Porphyromonas gingivalis, five Prevotella sp., ten isolates $P$. intermedia-nigrescens, seven Propionibacterium sp., three Proteus sp. and Selenomonas sp., nineteen isolates of Streptococcus spp., four Staphylococcus epidermidis, and five isolates of Veillonella sp.

The data presented in Table 1 show that imipenem was the most effective $\beta$-lactam, while variable levels of microbial resistance were observed for all other drugs. The association amoxicillin/clavulanic acid was effective against all isolates but one strain of Proteus sp., which produced $\beta$-lactamases active on amoxicillin, penicillin G, and cefoxitin and was not inhibited by clavulanic acid. Resistance to $\beta$-lactams was high among the Gram-negative anaerobes, such as Prevotella intermedianigrescens group and Veillonella sp. Resistance to metronidazole was confined to facultative anaerobes, although some Gram-positive strict anaerobes of genera
Peptostreptococcus and Bacteroides presented an intermediate susceptibility.

Resistance to benzylpenicillin and amoxicillin varied among the clinical strains, but most values of minimal inhibitory concentrations were closely related and showed the same pattern of â-lactamase production. Strains able to hydrolyze penicillin $\mathrm{G}$ were able to perform amoxicillin degradation. Ten (62.5\%) out of sixteen isolates resistant to benzylpenicillin and amoxicillin were $\beta$-lactamase producers, while all strains resistant to cefoxitin were able to produce these hydrolytic enzymes.

$\beta$-lactamase detection using biological and nitrocefin methods provided the same results, which are presented in Table 2 . There was a correlation between resistance to $\beta$-lactams and production of $\beta$-lactamases, which were active on penicillins and cephalosporins. Figure 1 presents the data referring to microbial resistance to $\beta$-lactams and $\beta$-lactamase production. There was a close correlation between resistance to $\beta$-lactams and production of $\beta$-lactamases. In strict anaerobes, $70 \%$ of all isolates resistant to $\beta$-lactams were $\beta$-lactamase producers, while $80 \%$ of all facultative isolates resistant to these drugs also produced such enzymes.

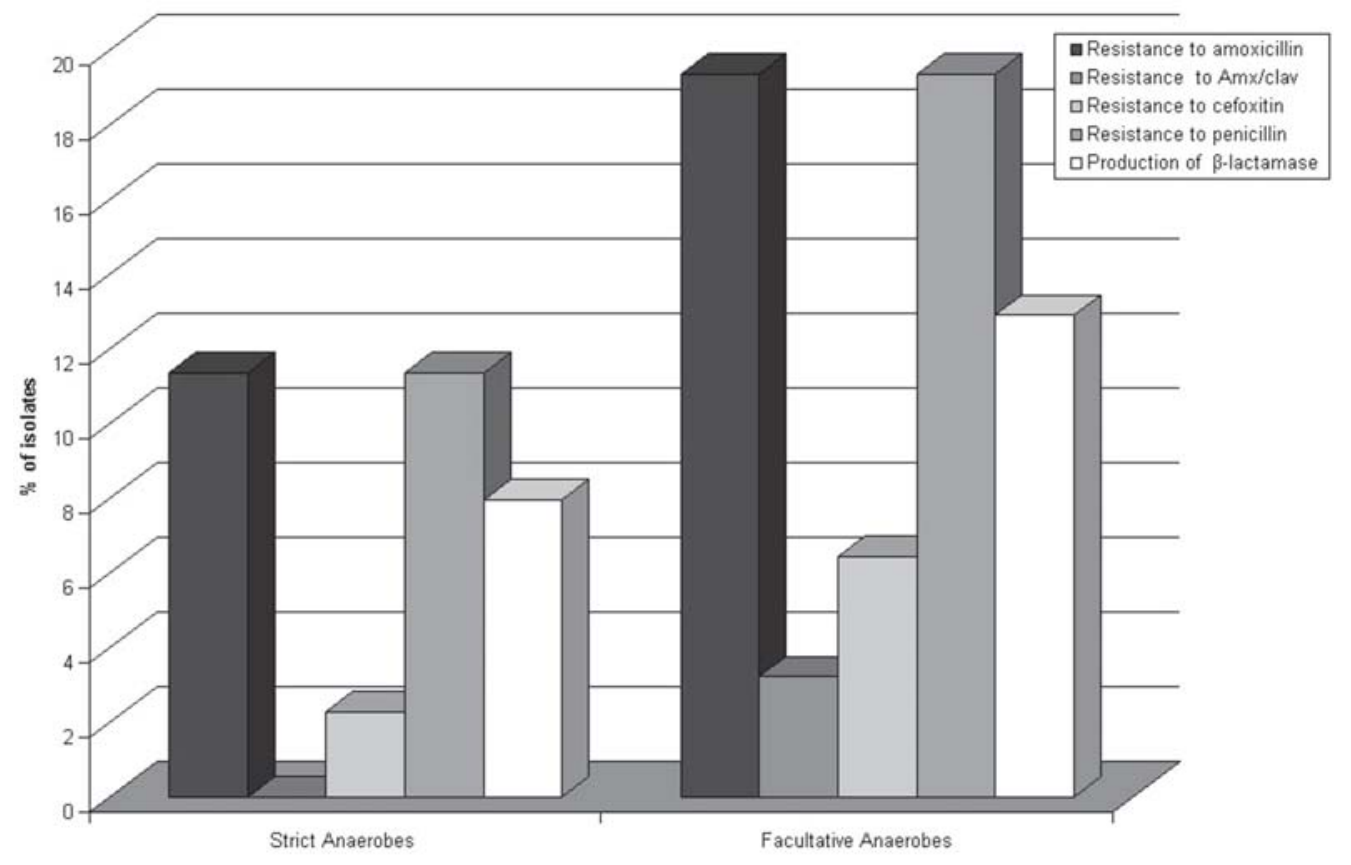

FIGURE 1- Resistance of strict and facultative anaerobes to $\beta$-lactams and production of $\beta$-lactamases 
TABLE 1- Resistance of 119 clinical isolates isolated from endodontic infections to metronidazole and $\beta$-lactams

\begin{tabular}{|c|c|c|c|c|c|c|}
\hline \multirow{2}{*}{$\begin{array}{l}\text { Isolate (tested number) and } \\
\text { antimicrobials }\end{array}$} & \multicolumn{3}{|c|}{$\%$} & \multicolumn{3}{|c|}{$\mathrm{MIC}(\mu \mathrm{g} / \mathrm{mL})$} \\
\hline & ${ }^{1} \mathbf{S}$ & ${ }^{2}$ & ${ }^{3} \mathrm{R}$ & Range & ${ }^{4} \mathrm{MIC}_{50}$ & ${ }^{5} \mathrm{MIC}_{90}$ \\
\hline \multicolumn{7}{|l|}{ Actinomyces spp. (9) } \\
\hline benzylpenicillin & 66.67 & 22.22 & 11.11 & $\leq 0.006-32$ & 0.125 & 32 \\
\hline amoxicillin & 66.67 & 22.22 & 11.11 & $\leq 0.006-32$ & 0.125 & 32 \\
\hline amoxicillin/clavulanic acid & 100 & 0.0 & 0.0 & $\leq 0.006-0.25$ & $\leq 0.006$ & 0.25 \\
\hline cefoxitin & 100 & 0.0 & 0.0 & $\leq 0.006-0.5$ & $\leq 0.006$ & 0.5 \\
\hline imipenem & 100 & 0.0 & 0.0 & $\leq 0.006-0.25$ & $\leq 0.006$ & 0.25 \\
\hline metronidazole & 66.67 & 33.33 & 0.0 & $\leq 0.006-16$ & 0.5 & 16 \\
\hline \multicolumn{7}{|l|}{ Bacteroides sp. (4) } \\
\hline benzylpenicillin & 75 & 0.0 & 25 & $\leq 0.006-256$ & 0.25 & 256 \\
\hline amoxicillin & 75 & 0.0 & 25 & $\leq 0.006-128$ & 0.25 & 128 \\
\hline amoxicillin/clavulanic acid & 100 & 0.0 & 0.0 & $\leq 0.006-1$ & 0.25 & 1.0 \\
\hline cefoxitin & 75 & 0.0 & 25 & $\leq 0.006-32$ & 0.125 & 32 \\
\hline imipenem & 100 & 0.0 & 0.0 & $\leq 0.006-8$ & 0.125 & 8 \\
\hline metronidazole & 100 & 0.0 & 0.0 & $\leq 0.006-16$ & 0.125 & 16 \\
\hline \multicolumn{7}{|l|}{ Eubacterium spp. (4) } \\
\hline benzylpenicillin & 100 & 0 & 0 & $\leq 0.006-0.5$ & $\leq 0.006$ & 0.5 \\
\hline amoxicillin & 100 & 0 & 0 & $\leq 0.006-0.25$ & $\leq 0.006$ & 0.25 \\
\hline amoxicillin/clavulanic acid & 100 & 0 & 0 & $\leq 0.006-0.25$ & $\leq 0.006$ & 0.25 \\
\hline cefoxitin & 100 & 0 & 0 & $\leq 0.006-0.5$ & $\leq 0.006$ & 0.5 \\
\hline imipenem & 100 & 0.0 & 0.0 & $\leq 0.006-0.5$ & $\leq 0.006$ & 0.125 \\
\hline metronidazole & 100 & 0.0 & 0.0 & $\leq 0.006-1$ & $\leq 0.006$ & 1 \\
\hline \multicolumn{7}{|l|}{ Enterococcus faecalis (5) } \\
\hline benzylpenicillin & 80 & 0.0 & 20 & $\leq 0.006-128$ & $\leq 0.006$ & 128 \\
\hline amoxicillin & 80 & 0.0 & 20 & $\leq 0.006-128$ & 0.125 & 128 \\
\hline amoxicillin/clavulanic acid & 100 & 0.0 & 0.0 & $\leq 0.006-0.5$ & $\leq 0.006$ & 0.5 \\
\hline cefoxitin & 80 & 0.0 & 20 & $\leq 0.006-128$ & $\leq 0.006$ & 128 \\
\hline imipenem & 100 & 0.0 & 0.0 & $\leq 0.006-2$ & 0.125 & 2 \\
\hline metronidazole & 0.0 & 0.0 & 100 & $32->512$ & 128 & $>512$ \\
\hline \multicolumn{7}{|l|}{ Fusobacterium spp. (17) } \\
\hline benzylpenicillin & 70.59 & 11.76 & 17.65 & $\leq 0.006-256$ & 0.125 & 8 \\
\hline amoxicillin & 70.59 & 11.76 & 17.65 & $\leq 0.006-256$ & 0.125 & 8 \\
\hline amoxicillin/clavulanic acid & 100 & 0.0 & 0.0 & $\leq 0.006-0.5$ & $\leq 0.006$ & 0.5 \\
\hline cefoxitin & 100 & 0.0 & 0.0 & $\leq 0.006-8$ & $\leq 0.006$ & 4 \\
\hline imipenem & 100 & 0.0 & 0.0 & $\leq 0.006-0.5$ & $\leq 0.006$ & 0.5 \\
\hline metronidazole & 100 & 0.0 & 0.0 & $\leq 0.006-0.5$ & $\leq 0.006$ & 0.5 \\
\hline \multicolumn{7}{|l|}{ Peptostreptococcus spp. (21) } \\
\hline benzylpenicillin & 85.72 & 9.52 & 4.76 & $\leq 0.006-16$ & $\leq 0.006$ & 0.5 \\
\hline amoxicillin & 90.48 & 4.76 & 4.76 & $\leq 0.006-16$ & $\leq 0.006$ & 0.5 \\
\hline amoxicillin/clavulanic acid & 100 & 0.0 & 0.0 & $\leq 0.006-0.5$ & $\leq 0.006$ & 0.5 \\
\hline cefoxitin & 100 & 0.0 & 0.0 & $\leq 0.006-2$ & $\leq 0.006$ & 1 \\
\hline imipenem & 100 & 0.0 & 0.0 & $\leq 0.006-0.5$ & $\leq 0.006$ & 0.5 \\
\hline metronidazole & 90.48 & 9.52 & 0.0 & $\leq 0.006-16$ & 0.125 & 2.0 \\
\hline \multicolumn{7}{|l|}{ Porphyromonas gingivalis (3) } \\
\hline benzylpenicillin & 100 & 0 & 0 & $\leq 0.006-0.5$ & $\leq 0.006$ & 0.5 \\
\hline amoxicillin & 100 & 0 & 0 & $\leq 0.006-0.25$ & $\leq 0.006$ & 0.25 \\
\hline amoxicillin/clavulanic acid & 100 & 0 & 0 & $\leq 0.006-0.25$ & $\leq 0.006$ & 0.25 \\
\hline cefoxitin & 100 & 0 & 0 & $\leq 0.006-0.5$ & $\leq 0.006$ & 0.5 \\
\hline imipenem & 100 & 0 & 0 & $\leq 0.006-0.25$ & $\leq 0.006$ & 0.25 \\
\hline metronidazole & 100 & 0 & 0 & $\leq 0.006-0.25$ & $\leq 0.006$ & 0.25 \\
\hline
\end{tabular}




\section{Cont.Table 1}

Prevotella spp. (15)

benzylpenicillin

amoxicillin

amoxicillin/clavulanic acid

cefoxitin

imipenem

metronidazole

Propionibacterium sp. (7)

benzylpenicillin

amoxicillin

amoxicillin/clavulanic acid

cefoxitin

imipenem

metronidazole

Proteus sp. (3)

benzylpenicillin

amoxicillin

amoxicillin/clavulanic acid

cefoxitin

imipenem

metronidazole

Selenomonas sp. (3)

benzylpenicillin

amoxicillin

$\begin{array}{lll}60 & 20 & 20 \\ 66.67 & 13.33 & 20 \\ 93.33 & 6.67 & 0.0 \\ 80 & 13.34 & 6.67 \\ 100 & 0 & 0 \\ 100 & 0 & 0\end{array}$

$\leq 0.006-512$

0.25

128

$\leq 0.006-256$

0.25

128

$\leq 0.006-2$

0.125

2

$\leq 0.006-128$

0.5

32

$\leq 0.006-1$

$\leq 0.006 \quad 1$

$\begin{array}{lll}100 & 0 & 0\end{array}$

$\leq 0.006-0.5$

$\leq 0.006$

0.5

$\begin{array}{lll}85.71 & 14.28 & 0.0 \\ 85.71 & 14.28 & 0.0 \\ 100 & 0.0 & 0.0 \\ 100 & 0.0 & 0.0 \\ 100 & 0.0 & 0.0 \\ 57.14 & 48.86 & 0.0\end{array}$

$\leq 0.006-16 \quad \leq 0.006 \quad 1$

$\leq 0.006-16 \quad 0.125 \quad 1$

$\leq 0.006-0.5 \quad \leq 0.006 \quad 0.5$

$\leq 0.006-2 \quad \leq 0.006 \quad 1$

$\leq 0.006-0.5 \quad \leq 0.006 \quad 0.5$

$\begin{array}{lll}\leq 0.006-16 & 2 & 16\end{array}$

amoxicillin/clavulanic acid

$\begin{array}{lll}0.0 & 33.33 \quad 66.67\end{array}$

$\begin{array}{lll}0.0 & 33.33 \quad 66.67\end{array}$

$1-256$

64

256

$0.0 \quad 66.67 \quad 33.33$

$\begin{array}{lll}0.0 & 33.33 \quad 66.67\end{array}$

$\begin{array}{lll}66.67 & 33.33 \quad 0.0\end{array}$

$\begin{array}{lll}0.0 & 0.0 & 100\end{array}$

$1-256$

64

256

4-32

32-256

$2-8$

$>512$

4

32

$128 \quad 256$

28

$>512 \quad>512$

cefoxitin

$100 \quad 0 \quad 0$

$100 \quad 0 \quad 0$

$100 \quad 0 \quad 0$

$100 \quad 0 \quad 0$

imipenem

100

0

metronidazole

Streptococcus spp. (19)

benzylpenicillin

amoxicillin

amoxicillin/clavulanic acid

cefoxitin

imipenem

metronidazole

Staphylococcus epidermidis (4)

benzylpenicillin

amoxicillin

$\begin{array}{lll}100 & 0 & 0\end{array}$

$\leq 0.006-0.5$

$\leq 0.006$

0.5

$\leq 0.006-0.25$

$\leq 0.006$

0.25

$\leq 0.006-0.25$

$\leq 0.006$

0.25

$\leq 0.006-0.5$

$\leq 0.006$

0.5

$\leq 0.006-0.25$

$\leq 0.006$

0.25

$\leq 0.006-0.25$

$\leq 0.006$

0.25

$84.21 \quad 10.52 \quad 5.26$

$\leq 0.006-16$

$\leq 0.006 \quad 1$

$89.48 \quad 5.26 \quad 5.26$

$\begin{array}{lll}100 & 5.26 \quad 0\end{array}$

$89.47 \quad 10.52 \quad 0$

$\begin{array}{lll}100 & 0 & 0\end{array}$

$21.06 \quad 10.52 \quad 68.42$

$\leq 0.006-16$

$\leq 0.006 \quad 1$

$\leq 0.006-0.25 \quad \leq 0.006 \quad 0.25$

$\leq 0.006-32 \quad 0.25 \quad 32$

$\leq 0.006-0.25 \quad \leq 0.006 \quad 0.25$

$21.06 \quad 10.52 \quad 68.42$

$1->512$

$\leq 0.006$

128

amoxicillin/clavulanic acid

$0,0 \quad 50 \quad 50$

$1->512$

$1->512$

$0.5-2$

2-128

$0.5-2$

$256->512$

1

$>512$

$0,0 \quad 50 \quad 50$

0,0

cefoxitin

imipenem

metronidazole

$75 \quad 25 \quad 0,0$

Veillonella sp. (5)

benzylpenicillin

$0,0 \quad 0,0 \quad 100$

$60 \quad 20 \quad 20$

$\leq 0.006-16$

$\begin{array}{ll}0.25 & 1 \\ 0.25 & -1\end{array}$

$60 \quad 20 \quad 20$

amoxicillin/clavulanic acid

100

$\leq 0.006-16$

0.25

1

$\leq 0.006-0.25 \quad \leq 0.006 \quad 0.25$

cefoxitin

$100 \quad 0$

$\leq 0.006-0.5$

$\leq 0.006$

imipenem

100

$\leq 0.006-0.25$

$\leq 0.006$

0.25

metronidazole

100

$\leq 0.006-0.25$

$\leq 0.006$

0.25

\footnotetext{
${ }^{1}$ Susceptible

${ }^{2}$ Intermediate

${ }^{3}$ Resistant

${ }^{4}$ Minimal Inhibitory Concentration for $50 \%$ of the isolates

${ }^{5}$ Minimal Inhibitory Concentration for $90 \%$ of the isolates
} 
TABLE 2- Production of $\beta$-lactamases by resistant microorganisms isolated from endodontic infections

\begin{tabular}{lccc}
\hline Microorganisms & \multicolumn{2}{c}{$\begin{array}{c}\text { Resistant isolates/ resistant isolates producers of } \begin{array}{c}\text { B-lactamases } \\
\text { Amoxicillin }\end{array} \\
\text { Cefoxitin }\end{array}$} & $0 / 0$ \\
\hline Actinomyces spp. & $1 / 0$ & $1 / 1$ & $1 / 0$ \\
Bacteroides sp. & $1 / 1$ & $1 / 1$ & $1 / 1$ \\
E. faecalis & $1 / 1$ & $0 / 0$ & $1 / 1$ \\
Fusobacterium spp. & $3 / 2$ & $0 / 0$ & $3 / 2$ \\
Peptostreptococcus spp. & $1 / 0$ & $1 / 1$ & $1 / 0$ \\
Prevotella spp. & $3 / 3$ & $1 / 1$ & $3 / 3$ \\
Proteus sp. & $2 / 1$ & $0 / 0$ & $2 / 1$ \\
Streptococcus spp. & $1 / 1$ & $1 / 1$ \\
S. epidermidis & $2 / 1$ & 0,0 & $2 / 1$ \\
Veillonella sp. & $1 / 0$ & $0 / 0$ & $1 / 0$ \\
Total & $16 / 10$ & $4 / 4$ & $16 / 10$ \\
\hline
\end{tabular}

\section{DISCUSSION}

Most studies that deal with the emergence of antimicrobial resistance of oral bacteria have been done in the western world and little information is available from developing countries ${ }^{1}$, which have socioeconomic and behavioral factors that promote bacterial resistance ${ }^{22}$, such as self-prescription and misuse. The resistance of strict and facultative anaerobic microorganisms has expanded considerably ${ }^{2,27}$, which has rendered traditional prescription habits critical in the absence of laboratorial exams. This fact is further aggravated when one considers the relevance of the phenomenon of self-medication in Brazil, which limits the efficacy of treatment and can make prescribing a difficult task, as it modifies the local patterns of susceptibility to drugs.

The use of antimicrobial drugs may constitute an important adjuvant in the treatment of endodontic and periapical infections, particularly in acute cases ${ }^{16}$, but it sometimes comes up against the problem of selection of microorganisms resistant to the most frequently used drugs. Moreover, this resistance is usually manifested by the production of enzymes that are able to degrade these drugs ${ }^{19}$, and anaerobic genera, such as Fusobacterium and Prevotella, are generally the main producers of these enzymes ${ }^{14,15,21}$, but they are highly sensitive to metronidazole ${ }^{1}$. The results listed in Table 1 are in accordance with these concepts, as resistance to most â-lactams seems to be frequently found in some genera, such as Prevotella and Fusobacterium and facultative rods and cocci.

The resistance to amoxicillin and penicillin $\mathrm{G}$ was significantly higher than previously reported in the literature concerning anaerobes from oral samples retrieved in developed countries $^{7,18,27}$, but the data were in accordance with data from developing countries ${ }^{1,3}$. Regarding the most frequently isolated facultative bacteria, genus Streptococcus, the resistance to $\beta$ lactams are slightly more elevated than those previously reported $^{4,5}$. Thus, the bacteria that accounted for the significantly increased proportion of resistance to amoxicillin and penicillin $\mathrm{G}$ in clinical samples were Gram-negative rods that inhabit periodontal pockets and gingival crevice ${ }^{7,9}$.

As the combination of amoxicillin/clavulanic acid was effective on almost all the isolates resistant to the other $\beta$ lactams (except for one isolate of Proteus sp.), as previously observed $^{2,11,13,19}$, it could be suggested that the mechanism of resistance to these drugs occurred due to the production of inactivating enzymes, although the action of some $\beta$-lactamases is not inhibited by addition of clavulanic acid ${ }^{13,18}$. In anaerobic Gram-negative bacteria, these $\beta$-lactamases are active on penicillins and cephalosporins ${ }^{27}$, as in accordance with the data presented in Table 2. On the other hand, the efficiency of imipenem on these bacteria highlights the need to leave the carbapenems for exclusive use in serious infections to avoid the dissemination of resistance.

The data shown in Table 1 substantiated the idea that clavulanic acid, a $\beta$-lactam devoid of antimicrobial activity but able to inhibit the action of an extensive group of enzymes that inactivate these drugs, and its associations with other $\beta$ lactams, may constitute an important option for prescription, particularly when the patient has a previous history of use of drugs of this group in the 2-3 preceding months.

In anaerobic Gram-negative bacteria, these $\beta$-lactamases are active on penicillins and cephalosporins ${ }^{27}$, as in accordance with the data presented in Table 2. Moreover, some isolates of genus Bacteroides and facultative anaerobes were resistant to amoxicillin, penicillin $\mathrm{G}$ and cefoxitin, the use of cephalosporins in substitution of penicillins in the treatment of serious mixed infections is compromised, especially in patients with history of previous use of penicillins. On the other hand, the efficiency of imipenem on these bacteria highlights the need to leave the carbapenems for use exclusively in serious infections to avoid the dissemination of resistance.

Some isolates that are resistant to $\beta$-lactams were proved not to be producers of $\beta$-lactamase by the methodology employed in this study (Table 2). This suggests that these bacteria are producers of non-exportable $\beta$-lactamases, as previously reported in Gram-negative bacteria ${ }^{12}$, or the existence of other mechanism of microbial resistance, such as alteration of structure of penicillin-binding proteins reducing the affinity to the $\beta$-lactams, or the method's sensitivity did not allow for the detection of these enzymes. 


\section{CONCLUSIONS}

The results of the present study indicate that, among the tested microorganisms, resistance to $\beta$-lactams was not disseminated and was more frequently found in some Gramnegative anaerobic rods, enteric microorganisms and facultative cocci. The resistance to these drugs was closely related to the production of $\beta$-lactamases. Resistance to metronidazole was observed only in facultative anaerobes.

\section{ACKNOWLEDGEMENTS}

This study was partially supported by FAPESP (Fundação de Amparo à Pesquisa do Estado de São Paulo; Grants 98/ 6555-2 and 03/12763-7).

\section{REFERENCES}

1- Al-Haroni MH, Skaug N,. Al-Hebshi NN. Prevalence of subgingival bacteria resistant to aminopenicillins and metronidazole in dental patients from Yemen and Norway. Int. J Antimicrob Agents. 2006;27:217-23.

2- Boyanova L, Kolarov R, Gergova G, Deliverska E, Madjarov J, Marinov $\mathrm{M}$, et al. Anaerobic bacteria in118 patients with deep-space head and neck infections from the University Hospital of Maxillofacial Surgery, Sofia, Bulgaria. J Med Microbiol. 2006;55:1285-9.

3- Brescó-Salinas M, Costa-Riu N, Berini-Aytés L, Gay-Escoda C. Antibiotic susceptibility of the bacteria causing odontogenic infections. Méd Oral Patol Oral Cir Bucal. 2006;11:70-5.

4- Chan Y, Chan CH. Antibiotic resistance of pathogenic bacteria from odontogenic infections in Taiwan. J Microbiol Immunol Infect. 2003;36:105-10.

5- Diaz-Mejia JJ, Carlos-Sausedo A, Amabile-Cuevas CF. Antibiotic resistance in oral commensal streptococci from healthy Mexicans and Cubans: resistance prevalence does not mirror antibiotic usage. FEMS Microbiol Lett. 2002;217:173-6.

6- Doern GV, Jones RN, Gerlach EH, Washington JA, Biedenbach DJ, Brueggemann A et al. Multicenter clinical laboratory evaluation of a beta-lactamase disk assay employing a novel chromogenic cephalosporin, S1. J Clin Microbiol.1995;33:1665-7.

7- Feres M, Haffajee AD, Allard K, Som S, Goodson JM, Socransky SS. Antibiotic resistance of subgingival species during and after antibiotic therapy. J Clin Periodontol. 2002;29:724-35.

8- Foschi F, Cavrini F, Montebugnoli L, Stashenko P, Sambri V, Prati C. Detection of bacteria in endodontic samples by polymerase chain reaction assays and association with defined signs in Italian patients. Oral Microbiol Immunol. 2005;20:289-95.

9- Fosse T, Madinier I, Hitzig C, Charbit Y. Prevalence of â-lactamase producing strains among 149 anaerobic Gram-negative rods isolated from periodontal pockets. Oral Microbiol Immunol. 1999;14:352-7.

10- Gomes BPFA, Pinheiro ET, Gadê CR Neto, Sousa ELR, Ferraz CCR, Zaia AA et al. Microbiological examination of infected dental root canals. Oral Microbiol Immunol. 2004;19:71-6.

11- Handal T, Olsen I, Walker CB, Caugant DA. â-Lactamase production and antimicrobial susceptibility of subgingival bacteria from refractory periodontitis. Oral Microbiol Immunol. 2004;19:303-8.
12- Handal T, Olsen I. Antimicrobial resistance with focus on oral betalactamases. Eur J Oral Sci. 2000;108:163-74.

13- Hecht DW. Prevalence of antibiotic resistance in anaerobic bacteria: worrisome developments. Clin Infect Dis. 2004;39:92-7.

14- Herrera D, Van Winkelhoff AJ, Dellemijn-Kippuw N, Winkel EG, Sanz M. Beta-lactamase producing bacteria in the subgingival flora of adult patients with periodontitis: a comparison between Spain and Netherlands. J Clin Periodontol. 2000;27:520-5.

15- Iwahara K, Kuriyama T, Shimura S, Williams DW, Yanagisawa M, Nakagawa $\mathrm{K}$ et al. Detection of $c f x A$ and $c f x A 2$, the â-lactamase genes of Prevotella spp., in clinical samples from dentoalveolar infection by Real-Time PCR. J Clin Microbiol. 2006;44:172-6.

16- Jacinto RC, Gomes BPFA, Ferraz CCR, Zaia AA, Souza FJ Filho. Microbiological analysis of infected root canals from symptomatic and asymptomatic teeth with periapical periodontitis and the antimicrobial susceptibility of some isolated bacteria. Oral Microbiol Immunol. 2003;18:285-92.

17- Jacinto RC, Gomes BPFA, Shah HN, FerrazCC, Zaia AA, Souza FJ Filho. Incidence and antimicrobial susceptibility of Porphyromonas gingivalis isolated from mixed endodontic infections. Int Endod J. 2006;39:62-70.

18- Koeth LM, Good CE, Appelbaum PC, Goldstein EJC, Rodloff AC, Claros M, et al. Surveillance of susceptibility patterns in 1297 European and US anaerobic and capnophilic isolates to co-amoxiclav and five other antimicrobial agents. J Antimicrob Chemother. 2004;53:103944.

19- Mättö J, Asikainen S, Väisänen M-L, Von Troil-Lindén B, Könönen E, Saarela M, et al. â-lactamase production in Prevotella intermedia, Prevotella nigrescens, and Prevotella pallens genotypes and in vitro susceptibilities to selected antimicrobial agents. Antimicrobial Agents Chemother. 1999;43:2383-8.

20- National Committee for Clinical Laboratory Standards. Methods for Antimicrobial Susceptibility Testing of Anaerobic Bacteria. $6^{\text {th }}$ ed. Approved Standard M11-A6. NCCLS Wayne, USA; 2004.

21- Nyfors S, Könönen T, Takal A, Jousemies-Somer H. â-lactamase production by oral Gram-negative species in infants in relation to previous antimicrobial therapy. Antimicrob Agents Chemother. 1999;43:15914.

22- Okeke IN, Lamikanra A, Edelman R. Socioeconomic and behavioral factors leading to acquired bacterial resistance to antibiotics in developing countries. Emerg Infect Dis.1999;5:18-27.

23- Olsen I, Dahlén G. Salient virulence factors in anaerobic bacteria, with emphasis on their importance in endodontic infections. Endod Topics. 2004;9:15-26.

24- Paula MO, Avila-Campos MJ, Gaetti-Jardim E Jr. Plasmid profile in oral Fusobacterium nucleatum from humans and Cebus apella monkeys. Rev Inst Med Trop São Paulo. 2003;45:5-9.

25- Sakamoto M, Siqueira JF Jr, Rôças IN, Benno Y. Bacterial reduction and persistence after endodontic treatment procedures. Oral Microbiol Immunol. 2007;22:19-23.

26- Sigurdsson A. Pulpal diagnosis. Endod Topics. 2003;5:12-25.

27- Wybo I, Pierard D, Verschraegen I, Reynders M, Vandoorslaer K, Delmee $\mathrm{M}$, et al. Third Belgian multicentre survey of antibiotic susceptibility of anaerobic bacteria. J Antimicrob Chemother. 2007;59:132-9. 